\title{
Factor analysis and classification of remotely sensed data for monitoring tidal flats*
}

\author{
Roland Doerffer \& Desmond Murphy \\ GKSS Forschungszentrum GmbH; Max-Planck-Straße, D-2054 Geesthacht, \\ Federal Republic of Germany
}

\begin{abstract}
Interest in using remote sensing techniques, principally those involving satellite, in Wadden Sea research has centred on attempting a classification of the various sediment surface types present. Unlike most recent studies which have used mainly Landsat Multispectral Scanner data, we have assessed the feasibility of using Landsat Thematic Mapper data, which in conjunction with time series aerial photography, forms the basis of a strategy for remotely sensing the Wadden Sea. This paper focusses on an approach for extracting potentially "hidden" within-pixel information from multispectral data sets. A hierarchical (unsupervised) classification of a Thematic Mapper image successfully classified five different classes, including land, saltmarsh, water, cloud and tidal flat areas. This procedure thus enabled a. "masking-out" of all classes other than those classified as tidal flat, following which a factor analysis was used to determine the minimum number of independent factors necessary to explain the observed variation in the signal received by the satellite. Three factors accounted for a total of $82 \%$ of the variation in all seven TM channels. Preliminary studies of the primary factor (score) image shows a good correlation with existing latterday cartographic data. Considering the proximate relationship between topography and other important biotic and abiotic sedimentary characteristics, this approach may prove valuable for future applications of satellite data for monitoring long-term change in physical and thus biological Wadden Sea characteristics. Ongoing research efforts are focussing on a classification and quantification of sub-pixel patchiness using aerial photography and ground surveys. The approaches taken and results obtained to date are discussed.
\end{abstract}

\section{INTRODUCTION}

The size, the variability over space and time, and the tides create severe logistical problems when monitoring the North Sea tidal flats along the Dutch, German and Danish coasts. Observations of the whole area, or large parts of it, by ship or by foot is both a time-dependent and time-consuming exercise, and for large areas, sampling may be restricted to a between-year strategy. Biological parameters and processes, such as the distribution and productivity of organisms, change with season, and may even change over days due to heavy storms or ground frosts. Furthermore, simultaneous samples of such phenomenon can rarely be obtained. With these problems in mind, satellite imagery and aerial photography can be, and have been used with some success in supporting

- Presented at the VI International Wadden Sea Symposium (Biologische Anstalt Helgoland, Wattenmeerstation Sylt, D-2282 List, FRG, 1-4 November 1988) 
mapping and monitoring programmes of the Wadden Sea. In this paper we will discuss, by way of examples of work presently being undertaken, some of the potentials and present limitations of this monitoring tool.

The two platforms, aircraft and satellites, offer different potentials and require different strategies for their application. Aerial photography has a mainly cartographic application in mapping the location of geological and hydrological structures. By using a time series of images taken within a tidal cycle, infrared photography has been successfully used for mapping land/water boundaries, thus deriving the topography of the tidal flats (Wegener, 1979).

Colour photography, and more particularly, false colour infrared photography has been used to map the distribution of benthic algae (Cameron, 1950; Grimes, 1971; Hubbard \& Grimes, 1972) and to subsequently estimate the biomass of certain areas (Meulstee et al., 1986, 1988; Gross et al., 1988).

Mapping the type of sediment using satellite data (chiefly Landsat Multispectral Scanner, MSS), has been carried out by several authors, and has been achieved mainly by means of multispectral classification techniques (Dennert-Möller, 1983; Folving, 1984; Wieland, 1984; Bartholdy \& Folving, 1986). One major problem in deriving conclusions from satellite data is the ground resolution of the scanning radiometer, which is usually in the order of tens of metres. The use of aerial photography for classification purposes overcomes this problem to some extent in that the ground resolution is in the order of centimetres. Examples of the use of aerial photography in tidal flat and saltmarsh studies are numerous (Pestrong, 1969; Wallentinus \& Jonson, 1972; Anderson \& Wobber, 1973; Reimold et al., 1973; Sehers \& Tueller, 1973; Steffensen \& McGregor, 1976). A good example of its use on a tidal flat is that of Michaelis et al. (1982) in which they were able to differentiate between twenty-seven different classes ranging from biological to geophysical in origin. However, multispectral classification of aerial photographs is limited since in case of true or false colour photography only three rather broad spectral bands within the visible or near-infrared are available.

With respect to sediment surface characteristics there are a number of difficulties encountered in the interpretation of the radiance spectra of a single pixel. The main problem, particularly for satellite images, lies in the fact that within the area circumvented by the footprint of the radiometer it is possible to find small patches of algae, mussle shells etc., each of which have a different spectral reflectance. Consequently, the spectral information contained in a pixel (i.e. picture element) is an integral of the spectral radiances from the different objects present on the sediment surface within this area. In the case of Landsat MSS the pixel size corresponds to a footprint on the ground of $79 \mathrm{~m} \times 56 \mathrm{~m}$. For the Landsat Thematic Mapper (TM) radiometer this footprint size is smaller (i.e. $30 \mathrm{~m} \times 30 \mathrm{~m}$ ), but even within this small area a mixture of different surface types can lead to ambiguous interpretations of the radiance spectra.

A closely related problem often encountered in the classification of different surface types is that tidal flat sediments, for example, are distributed along a continuum between sand and mud. The sharp boundaries one finds on land, such as between forest and agricultural areas, are absent. This is also true for biological components such as green macroalgae which can exhibit extensive spatial and temporal overlap. In tidal situations, this problem is further compounded by the varying degrees of water coverage of areas similar in surface type. This phenomenon can also modify the backscattered radiation 
spectrum. Furthermore, the difference in spectral signal between two similar types may not be sufficient for a distinct separation to be made.

\section{REMOTE SENSING STRATEGY}

Considering all these obstacles to the application of remote sensing in support of monitoring and mapping programmes of the Wadden Sea, the goal of the present paper is threefold:

(1) To assess the feasibility of using Landsat TM data for a classification of the Wadden Sea. Then, accepting that each pixel is potentially made up of patches of different surface types and that it is not possible to retrieve the surface properties from the radiance spectra directly (i.e. by having both the spectral reflectance characteristics of each object and the prevailing atmospheric properties), we will thus approach this problem from a different perspective. This will be done by using factor analysis, to see how all the sub-pixel covariates (e.g. water content, grain-size, algal cover, temperature etc.) contribute to the overall between-pixel variation in the images of all seven TM channels. In other words we want to find the underlying variable (factor) which can explain most of the variation in the seven TM channels.

(2) By showing some preliminary results, to highlight the temporal variability of the biological system within an area equivalent to a TM pixel.

(3) Finally, to outline a strategy of how to obtain the most useful information from remotely sensed data for monitoring the Wadden Sea. To achieve this, the strategy is dependent on the temporal and spatial resolving power of both airborne and satellite sensors and will be divided into two parts, namely:

(i) Mapping and monitoring the whole Wadden Sea area, or large parts of it, is the domain of satellite remote sensing. The primary reason for this is that the high costs involved and the amount of data one would have to handle excludes the use of aerial remote sensing. By using the near infrared channels one can map the distribution of water channels, sandbanks, and thus monitor changes in tidal flat morphology over a number of years or decades. The classification and factor analysis of the spectral information obtained by satellite of a given area can be used to map areas with identical or similar surface types. This can then be used as a basis for detailed ground mapping, and can help reduce the number of ground samples and measurements required while simultaneously improving the representativeness of the samples with respect to the surrounding areas. Furthermore, on the basis of such satellite-derived maps a yearly updating of maps could be done by monitoring only those areas where changes are detected.

(ii) Aerial remote sensing using photography and/or optoelectronic multispectral scanners is best applied in situations where small-scale patches require a high spatial resolution or where data with a high temporal resolution (e.g. monitoring seasonal/tidal changes) are required. Furthermore, an aerial survey can be exactly scheduled to overlap with particular events such as supporting field experiments or monitoring specific areas after events, such as a storm or an oil spillage, have occurred. Weather limitations are less critical as surveys can also be carried out under clouds.

For both tasks - satellite and aerial survey - we will give an example in the form of a case study of which steps we have used to retrieve the information. 


\section{ANALYSIS OF A THEMATIC MAPPER SCENE BY UNSUPERVISED HIERARCHICAL CLASSIFICATION AND FACTOR ANALYSIS}

Thematic Mapper is a multispectral scanner flying on the NASA/EOSAT satellite, LANDSAT 5. It has seven channels whose range in the visible and near infra-red extends between $0.45 \mu \mathrm{m}$ and $2.35 \mu \mathrm{m}$ and has one thermal channel the range of which lies between 10.4-12.5 $\mu \mathrm{m}$ (see Table 1). The spatial resolution in the visible and nearinfrared is $30 \mathrm{~m} \times 30 \mathrm{~m}$ and in the thermal infrared channel it has a ground resolution of $120 \mathrm{~m} \times 120 \mathrm{~m}$.

The TM scene used for the classification of the Wadden Sea was obtained on 17 May, 1986.

The overflight time of the Landsat satellite is $1045 \mathrm{~h}$ Middle European Summertime.

An area northeast of the Island of Pellworm and south of the island of Gröde in the North Frisian Wadden Sea was chosen for this analysis (Fig. 1). The corresponding false colour TM image of this area is shown in Figure 2. On the 17 May 1986, low-water at Husum and at Cuxhaven occurred at $1345 \mathrm{~h}$ and $1334 \mathrm{~h}$, respectively.

The software we have developed for the digital analysis of images is based on a program package by Rose \& Schultz (1978).

\section{Classification}

Our first step was to identify tidal flat areas not covered by water in this subscene. This was done by means of an unsupervised (i.e. no training areas) hierarchical classification using the K-means cluster algorithm (Späth, 1975). The criterion for class separation of pixel grey levels is based on the squared Euclidean distance between the centre of each cluster (i.e. class), the centre in this case being the mean of the pixel grey levels in each cluster. After deciding on the number required, clusters are formed by the association of data points (pixel grey levels) with their closest cluster centre. New clusters or new

Table 1. Spectral channels of Landsat-5 Thematic Mapper and some of their potential applications

\begin{tabular}{|c|c|c|}
\hline Channel & Range & Potential applications \\
\hline 1 & $0.45-0.52 \mu \mathrm{m}$ & $\begin{array}{l}\text { Soil and vegetation separation; mapping coastal waters; differ- } \\
\text { entiating between deciduous and coniferous species }\end{array}$ \\
\hline 2 & $0.52-0.60 \mu \mathrm{m}$ & $\begin{array}{l}\text { Vigour of vegetation can be discriminated by chlorophyll absorp- } \\
\text { tion measurements }\end{array}$ \\
\hline 3 & $0.63-0.69 \mu \mathrm{m}$ & $\begin{array}{l}\text { Plant species can be discriminated by chlorophyll absorption } \\
\text { measurements }\end{array}$ \\
\hline 4 & $0.76-0.90 \mu \mathrm{m}$ & $\begin{array}{l}\text { Biomass content can be determined; water bodies can be deline- } \\
\text { ated }\end{array}$ \\
\hline 5 & $1.55-1.75 \mu \mathrm{m}$ & $\begin{array}{l}\text { Clouds and snow can be differentiated } ; \text { vegetation and soil mois- } \\
\text { ture can be measured }\end{array}$ \\
\hline 6 & $10.4-12.5 \mu \mathrm{m}$ & $\begin{array}{l}\text { Thermal mapping; soil moisture can be determined; plant heat } \\
\text { stress can be measured }\end{array}$ \\
\hline 7 & $2.08-2.35 \mu \mathrm{m}$ & Hydrothermal mapping; rock types can be discriminated \\
\hline
\end{tabular}




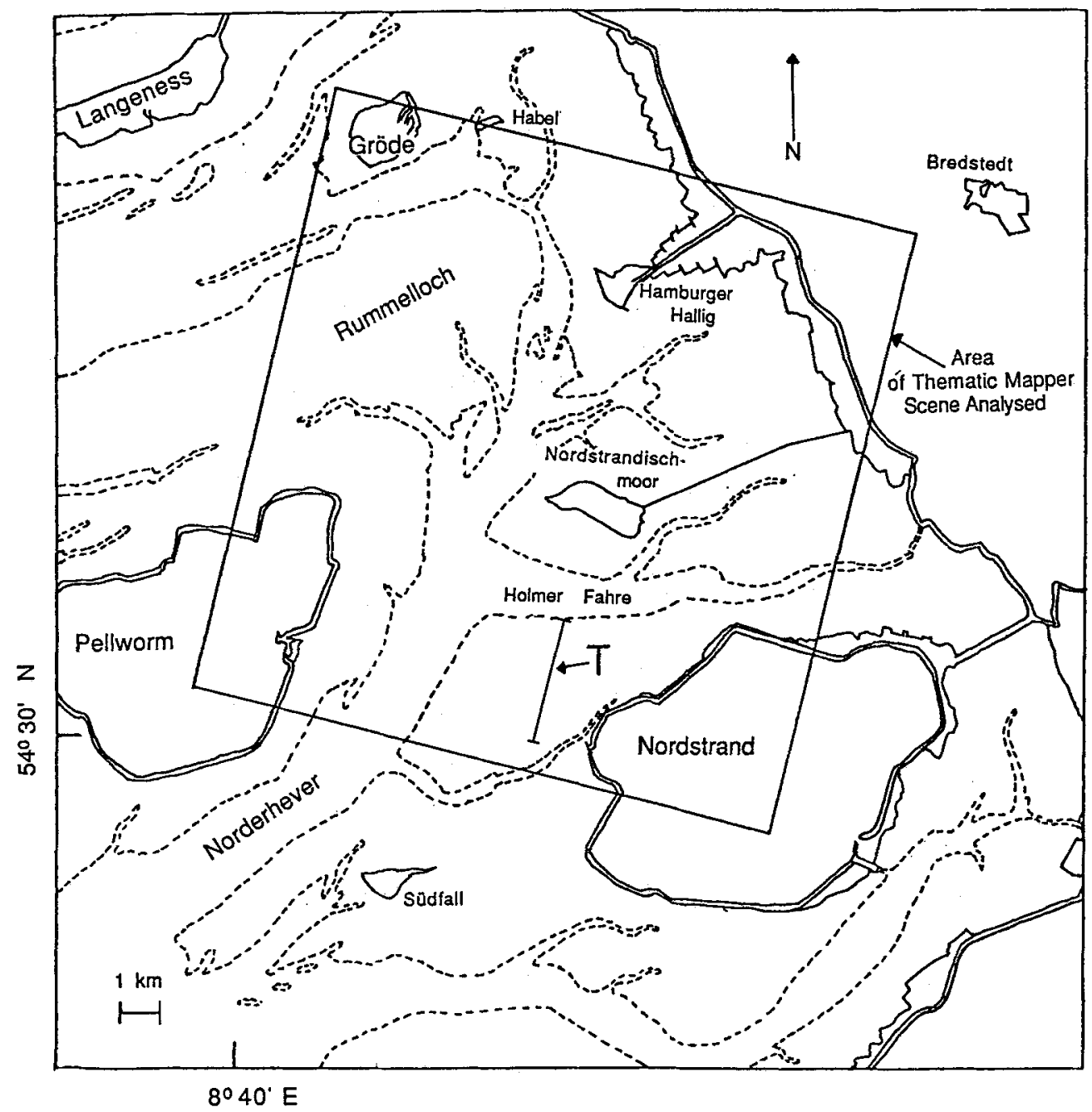

Fig. 1. Part of the North Frisian Wadden Sea area (from the Deutsches Hydrographisches Institut, 1978) showing test area (bounded) for the classification and factor analyses, and showing also the transect $(\mathrm{T})$ used for comparing pixel grey level and topography

branches of the hierarchical tree are formed by an iterative procedure in which those clusters with the greatest sum-of-squares error are divided into new classes.

The classification scheme and the result obtained are shown in Figures 3 and 4 , respectively. As illustrated, five classes were all that were necessary for a clear separation of tidal flat areas from other classes in the scene. This was achieved by merging channel 4 (which has a strong tidal flat signal), channel 5 (which has a strong water signal) and channel 6 (the thermal channel). The other classes included water, land, foreland (Salzwiesen) and cloud.

Only those pixels representing the tidal flat class were subsequently used in the 


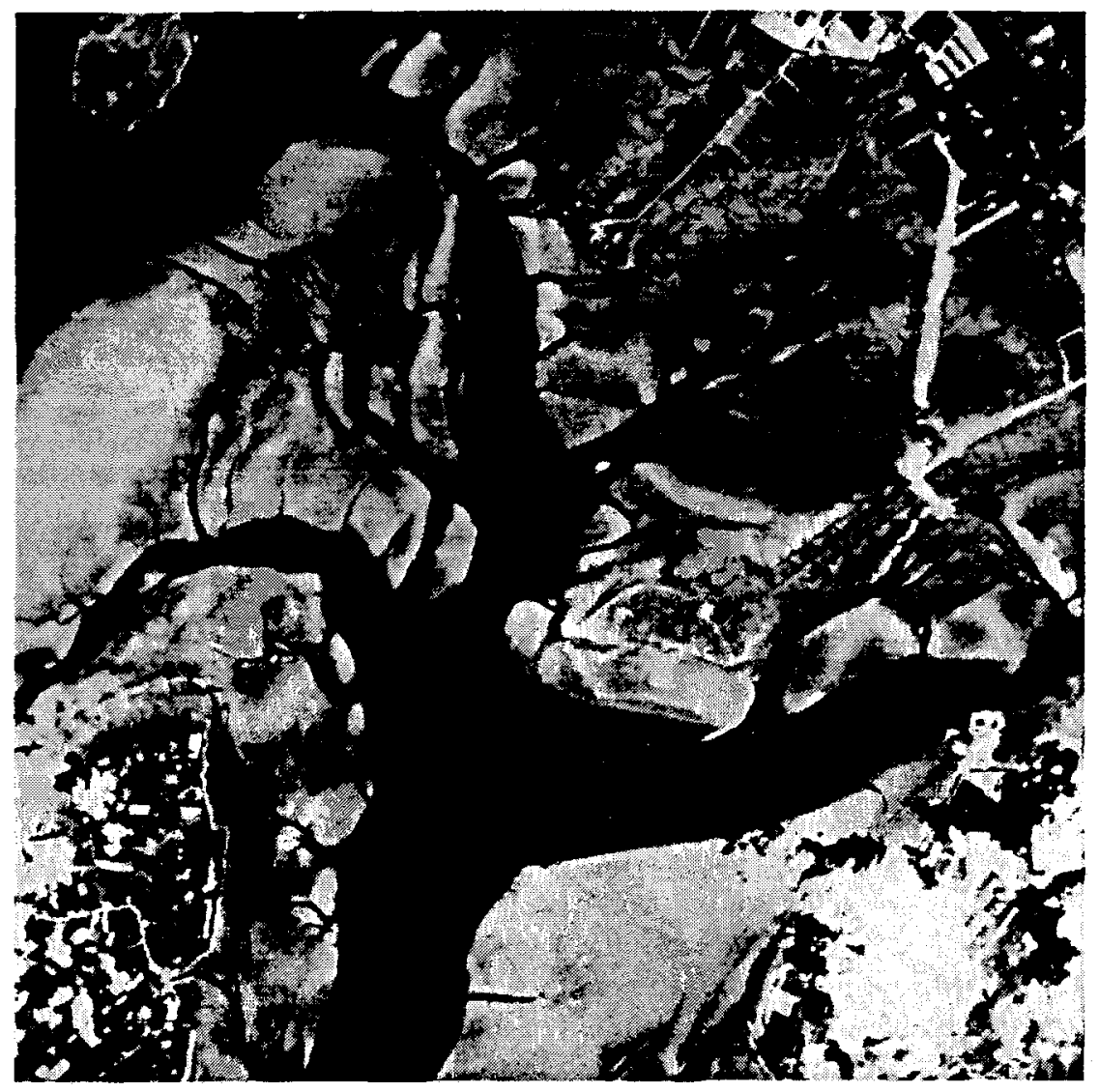

Fig. 2. False colour satellite image of the area bounded in Figure 1 and produced by merging channels 3,4 and 5 (see Table 1)

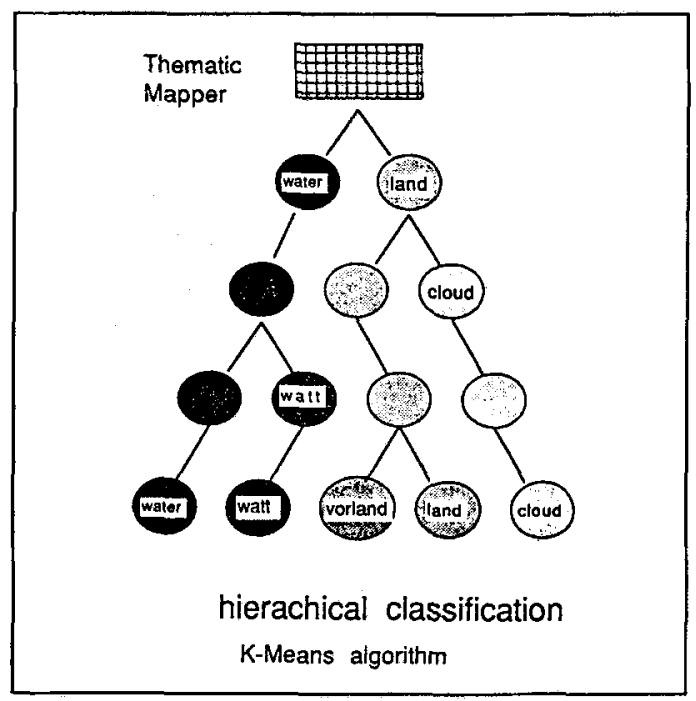

Fig. 3. Classification scheme showing five classes (i.e. water, cloud, saltmarsh, mudflat and land) 


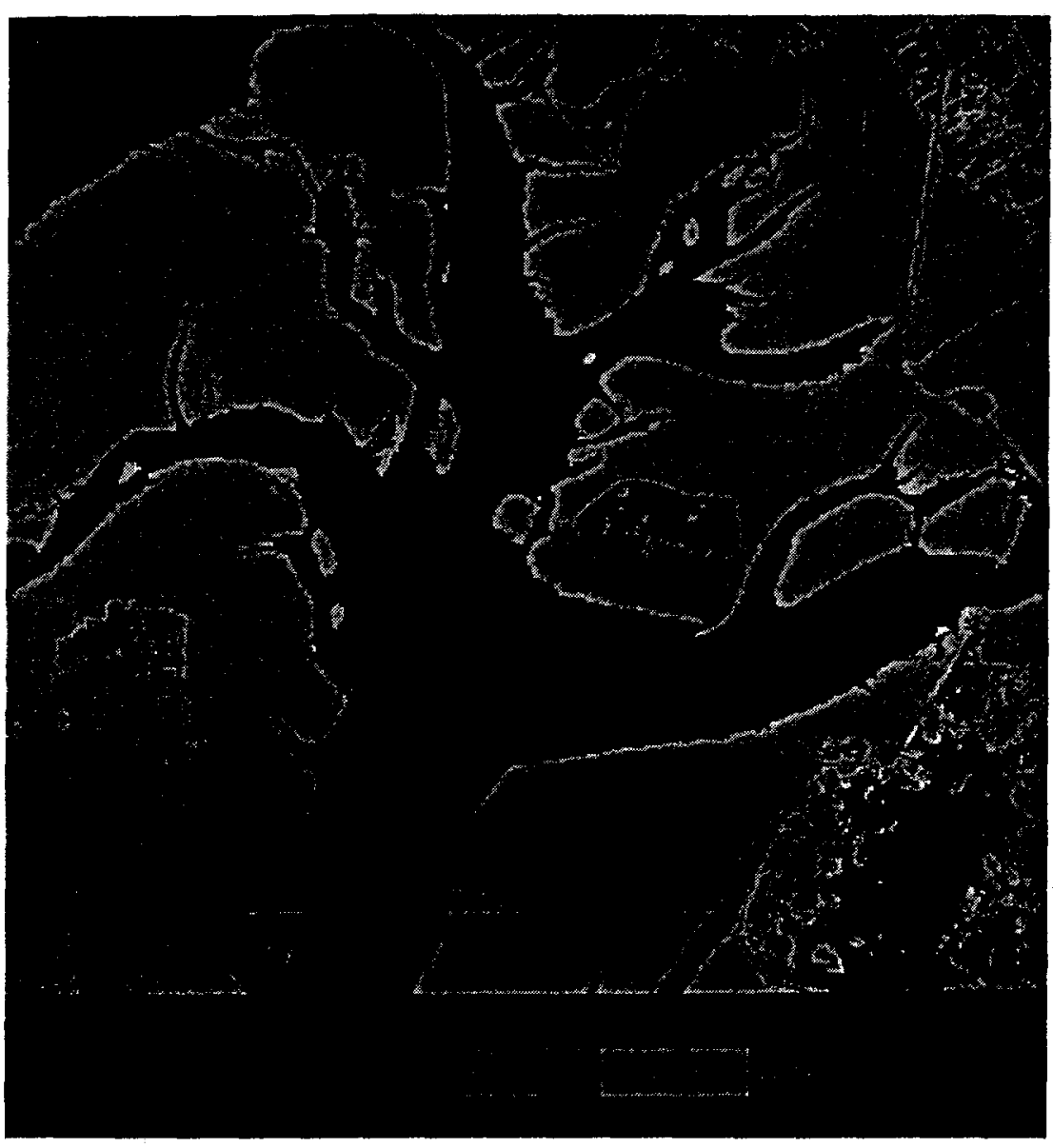

Fig. 4. Corresponding visual representation of the classification of classes water, cloud, saltmarsh, tidal flats and land as outlined in Figure 3

factor analysis (i.e. all other classes were masked out). This restriction is necessary since the other significantly different classes, cloud, water, land and foreland (Salzwiesen) would alter the covariance matrix (see below) and thus lead to erroneous conclusions concerning factors unique to tidal flat areas only.

\section{Factor analysis}

Factor analysis has its origins as a statistical technique in attempting to provide mathematical models to explain theories concerning human psychology and behaviour. In essence, factor analysis focusses on uncovering the related or patterned variation between a set of input variables. This is accomplished by an analysis of the linear correlations between the variables such that a set of new variables or factors, smaller in number than the original number of variables, is resolved. In depth descriptions of the 
philosophy underlying, and the methods involved in factor analysis can be found in Rummel (1970), Überla (1971), Harman (1976), Cattell (1977) and, more generally, in Maxwell (1977).

Our basic idea for using this method is as follows: the distribution of different sediment types and organisms can be explained by a few proximate phenomena (i.e. factors) of which topography is assumed as being one of the more dominating. It dictates the period of water coverage during a tidal cycle, the water content in the sediment, and other physicochemical parameters such as temperature or the oxygen content of the sediment.

The spectral reflectivity, on the other hand, depends on the sediment type, the water content, and the coverage by organisms such as benthic diatoms, macroalgae or mussel shells on the sediment surface. Since the spatial distribution of these variables and their corresponding reflectivity in a number of spectral bands will have a high degree of covariance, it should be possible to retrieve a set of factors from the covariance matrix (which is made up of the spectral radiances of the pre-classified tidal flat area) by using the mathematical formalism of the factor analysis. This method is based on principle component analysis, and as such, by rotating the coordinate system within the multidimensional vector space, one can achieve minimal or maximal correlation between the factors and the variables.

The results are factor loadings which describe the correlation between the variables (i.e. the normalized radiances in the seven spectral channels) and the factors. This relationship can be used to interpret the factors if one knows the optical properties of the surface objects which might be visible in the spectral bands of the TM scene. Figure 5 diagrammatically outlines our idea for using factor analysis in retrieving important tidal flat parameters from the multispectral radiance data of the satellite.

\section{Interpretation}

Before an interpretation of the factor loading spectrum is possible, several points should be noted initially. Firstly, it can be stated that the channels effectively formed three different groups (see Table 2) with channels 1,2 and 3 being highly correlated (group 1), and channels 5 and 7 and to a lesser extent channel 4 being highly correlated (group 2). Channel 6 (i.e. group 3) shows little or no correlation with any of the other channels, and this is because its wavelength range is in the emissive thermalinfrared region of the electromagnetic spectrum.

Secondly, three dominating eigenvectors can be calculated from the covariance matrix of the spectral radiances (pixel grey levels) (Fig.6). After orthogonal rotation (using the Varimax criterion; see Rummel, 1970; Überla, 1971) three independent factors are obtained which together account for $82 \%$ of the variation in all seven TM channels. The first two factors alone account for a total of $72 \%$ of the total variation (Table 3). The column labelled $\mathrm{H}^{2}$ (i.e. the communality, Table 3 ) reflects the proportional contribution of each of the seven channels to the total variance accounted for by the three factors. It is clear that channels 5 and 3 provide the greatest contribution. Channel 5 seems to be best at resolving tidal flats not covered or saturated with water. Channel 3 on the other hand is good at resolving water.

These results thus enabled the calculation of the factor loadings through the correla- 


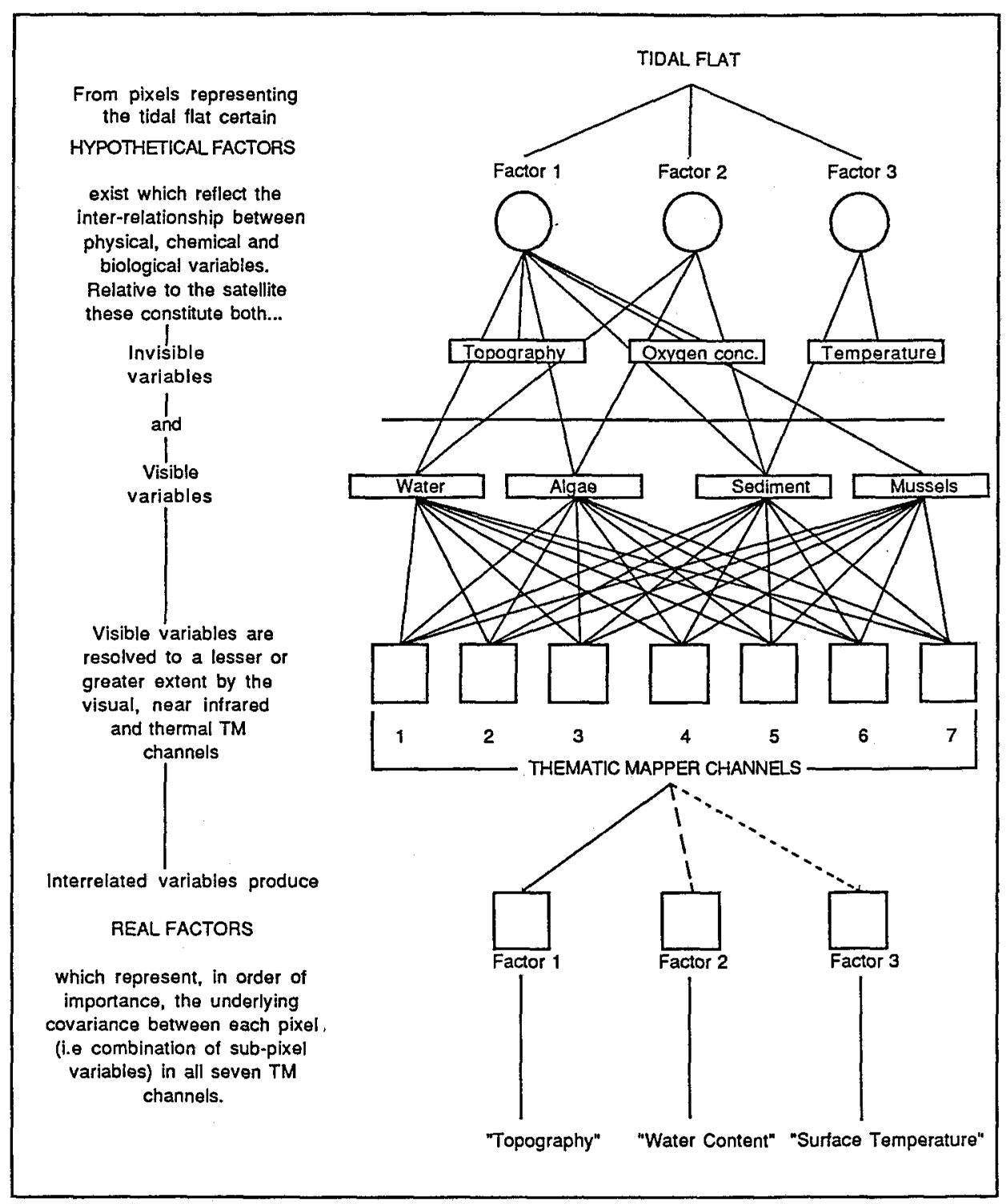

Fig. 5. Flow diagram as to how hypothetical factors and real factors derived from radiance spectra are related in the factor analysis

tion of the normalized pixel grey levels with each of the three factors. As shown in Figure 6, the variances in channels 1,2 and 3 are important in Factor 1, whereas channels 5,7 and to a lesser extent channel 4 contribute more to Factor 2 . In the case of Factor 3 , channel 6 is the predominant influence with perhaps a small contribution from channel 4 .

An interpretation of these results is greatly assisted by calculating the factor scores for each factor. These scores permit a visual representation of each factor in each pixel of 
Table 2. Correlation matrix of the relationship between tidal flat pixels only, in the seven TM channels and the communality. For further explanation see text

\begin{tabular}{rrrrccccc|}
\hline & 1 & 2 & 3 & 4 & 5 & 6 & 7 & $\mathrm{H}^{*} 2$ \\
\hline 1 & 1.000 & 0.912 & 0.907 & 0.341 & 0.104 & -0.306 & 0.178 & 0.912 \\
2 & 0.912 & 1.000 & 0.986 & 0.394 & 0.054 & -0.226 & 0.120 & 0.986 \\
3 & 0.907 & 0.986 & 1.000 & 0.318 & 0.019 & -0.175 & 0.086 & 0.986 \\
4 & 0.341 & 0.394 & 0.318 & 1.000 & 0.516 & -0.231 & 0.481 & 0.516 \\
5 & 0.104 & 0.054 & 0.019 & 0.516 & 1.000 & 0.216 & 0.945 & 0.945 \\
6 & -0.306 & -0.226 & -0.175 & -0.231 & 0.216 & 1.000 & 0.159 & 0.306 \\
7 & 0.178 & 0.120 & 0.086 & 0.481 & 0.945 & 0.159 & 1.000 & 0.945 \\
\hline
\end{tabular}
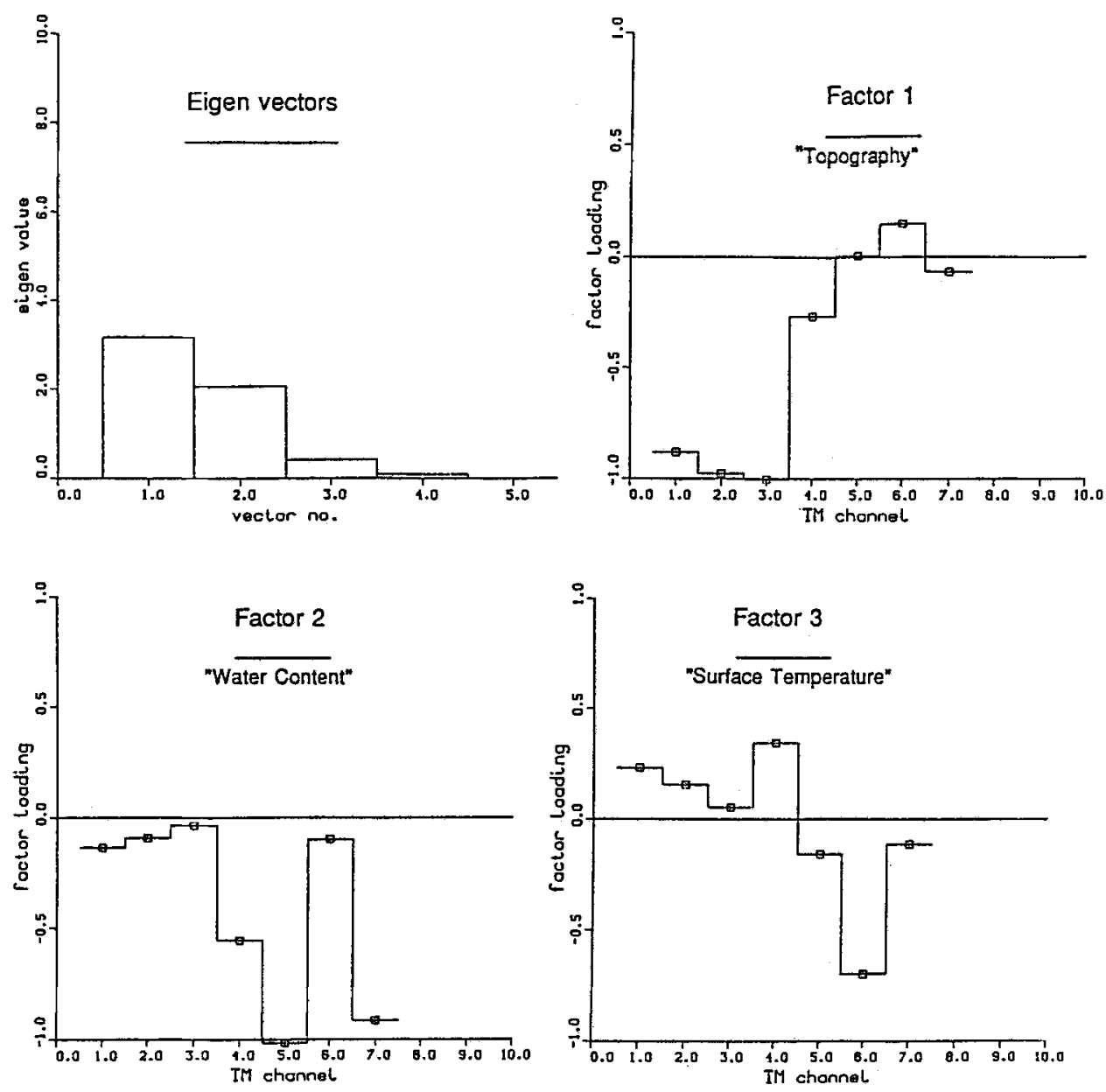

Fig. 6. Eigenvalues and the factor loadings seen as the relative contribution of each channel in each factor 
Table 3. Rotated factor matrix of tidal flat pixels only, showing factor loadings, the variance among all seven channels that is accounted for by each factor (i.e. as a percent of that accounted for by all factors), and the communality (i.e. the proportion of the total variance accounted for by each channel). For further explanation see text

\begin{tabular}{|crrrr|}
\hline & F 1 & F 2 & F 3 & $\mathrm{H}^{* * 2}$ \\
\hline 1 & -0.882 & -0.135 & 0.231 & 0.849 \\
2 & -0.977 & -0.091 & 0.156 & 0.987 \\
3 & -1.004 & -0.035 & 0.054 & 1.012 \\
4 & -0.267 & -0.555 & 0.342 & 0.496 \\
5 & 0.007 & -1.018 & -0.158 & 1.061 \\
6 & 0.148 & -0.098 & -0.696 & 0.516 \\
7 & -0.067 & -0.913 & -0.113 & 0.851 \\
VAR & 2.837 & 2.215 & 0.720 & 5.771 \\
$\%$ & 40.530 & 31.638 & 10.279 & 82.447 \\
\hline
\end{tabular}

an image. The factor score for each pixel is calculated by a linear combination of the seven channels weighted with the regression coefficients.

To test our reasoning that topography is one of the most important tidal flat parameters against that of the factor analysis results, a comparison was made between the pixel grey level of Factor 1 score image and tidal height on the flats. The topographical data was obtained from a transect, beginning west of the island of Nordstrand and extending north-east in the direction of the Holmer Fähre channel, on the Kuratorium für Forschung und Küsteningenieurwesen Chart, No. 1418 (see Fig. 1). This particular area was mapped in 1974, and is one of the more recently surveyed areas.

The result as shown in Figure 7 shows a surprisingly good correlation between the two parameters. It should be stressed, however, that it is not necessarily topography which is reflected in the pixel grey levels of the factor score image, but rather a combination of the radiated signals from all the covarying variables, such as algal cover, sediment grain size etc., which are dependent on topography and all of which influence the images produced in the different TM channels. The result, although promising in that it opens up the possibility 'of a new area of application in terms of using satellite information for monitoring changes in the Wadden Sea, is, however, in need of further testing.

A visual comparison between the factor score image of Factor 2 and the original and separately classified images of channels 4 and 5, strongly suggests that the water content of the sediment is responsible for the second most important source of variation in all seven TM channels. These findings are not unlike those obtained by Folving (1984). Using principle component analysis on both airborne multispectral data and Landsat MSS imagery, he concluded that the first principle component correlated well with "general sedimentological features", while the second principle component was strongly related to "water features" of the Danish Wadden Sea.

The result for Factor 3 is similar to that recently obtained by Doerffer et al. (1989) in that the thermal infra-red channel 6 has the greatest contribution to the percentage variation accounted for by this factor. Thus, this factor probably represents a combination of both the tidal flat and atmospheric thermal environments. 


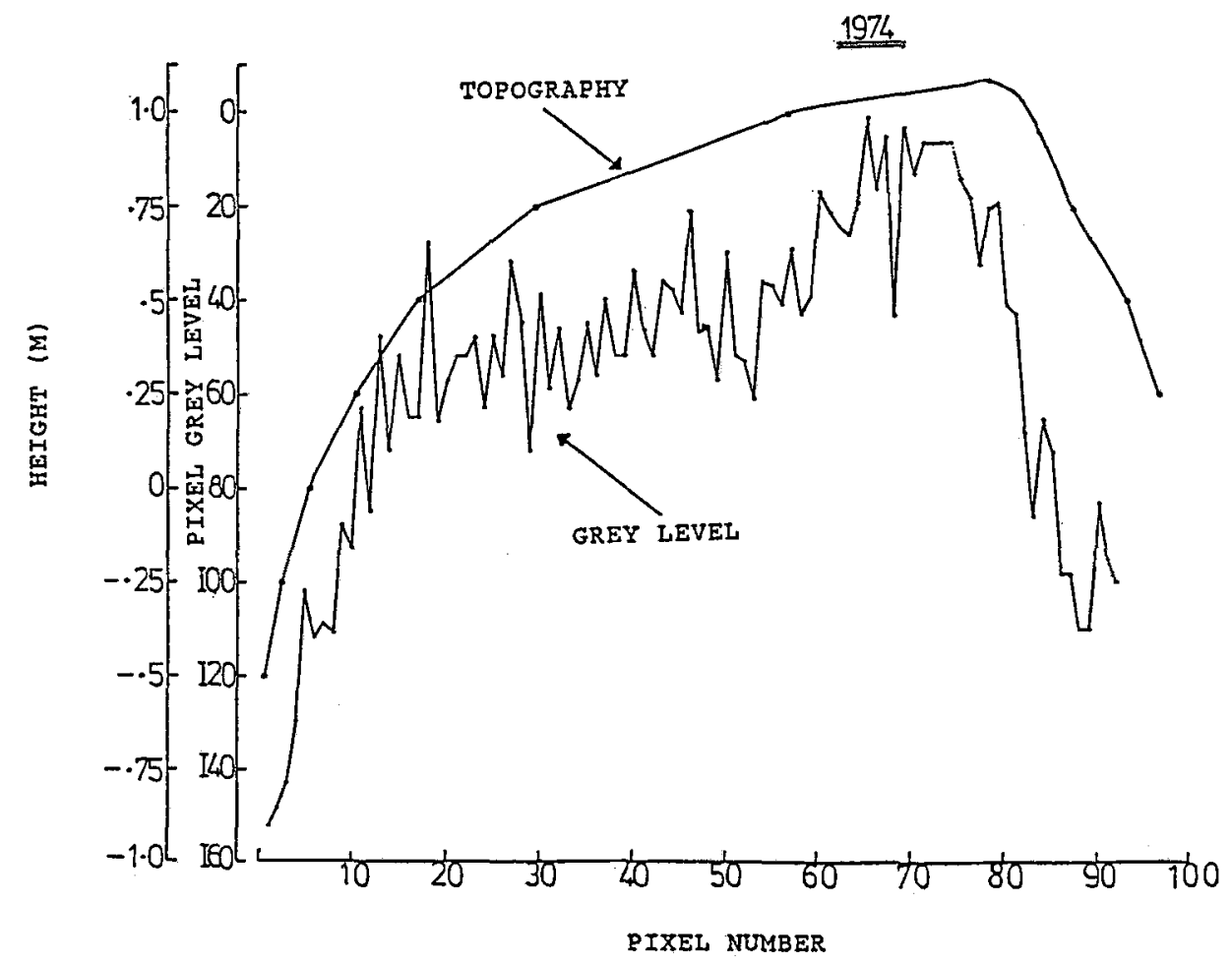

Fig. 7. Relationship between the pixel grey level (i.e. pixel density) and topography for an area west of Nordstrand and extending north east to the Holmer Fähre (see Fig. 1)

From these results we can say that factor analysis can be used to map the horizontal distribution of a small number of proximate factors which determine sediment surface characteristics and thus the optical properties of the area. Changes in these variables should indicate changes in the ground variables. However, the nature of these variables has to be verified by ground control analyses.

\section{SUB-PIXEL PATCHINESS}

As noted earlier one of the main concerns relating to satellite imagery is the size of pixel footprint on the ground. This concern stems from the sometimes small-scale heterogeneous spatial distribution of surface types. Aerial photography can easily overcome this problem with its greater resolving power, but in terms of multispectral classification is somewhat limited since both true-colour and false-colour films have only three rather broad spectral bands within the visible and infra-red regions, respectively. The use of airborne radiometers (such as the Optical Multichannel Analyser) combines a high spectral resolution with a very large number of small-band spectral channels ranging from the visible to thermal infrared. These, however, have only seldom been used (e.g. Folving 1984), and this is due mainly to the high costs involved in both operating and processing the data. 


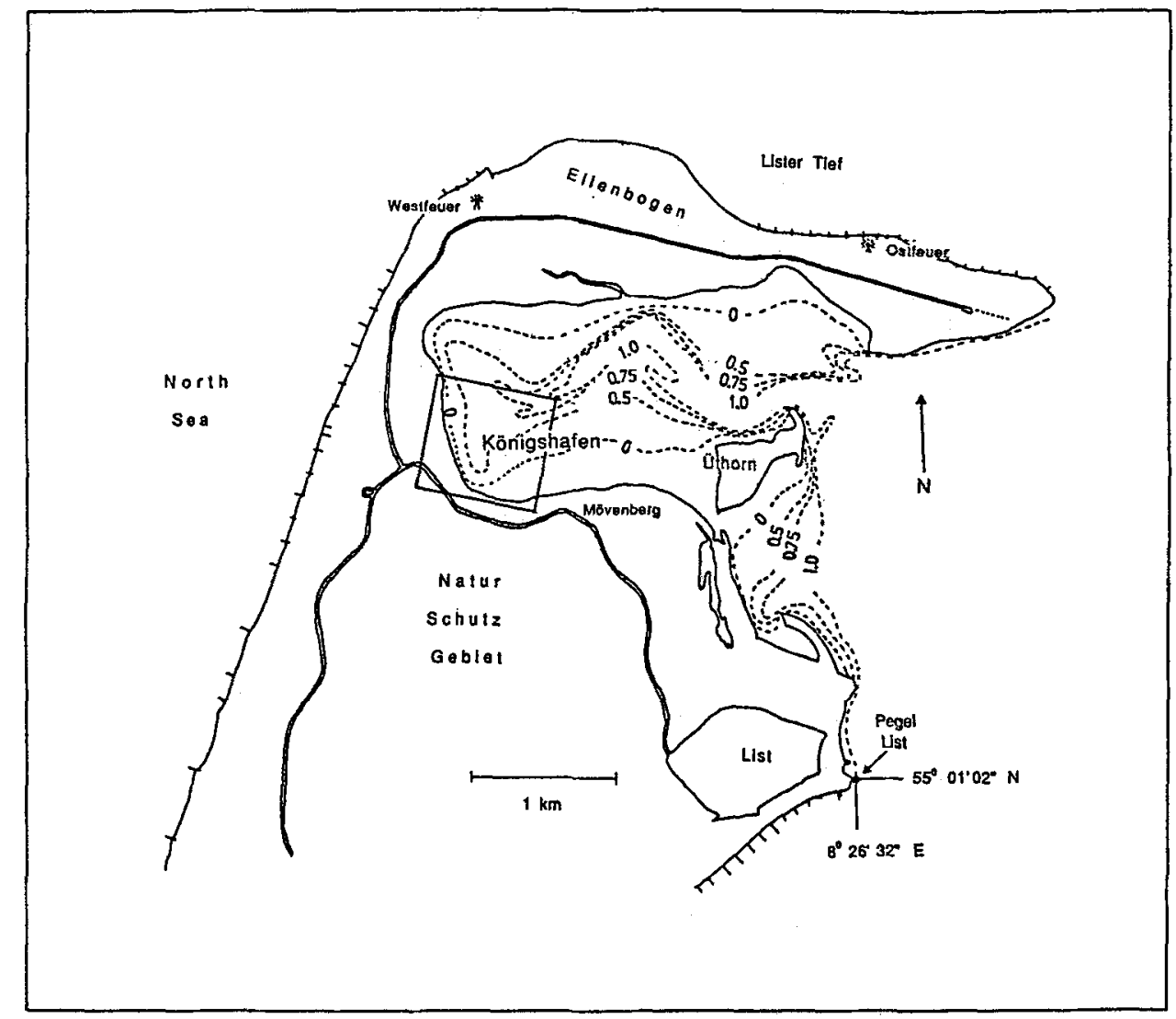

Fig. 8. Aerial and ground truth surveys were carried out in the Königshafen area, situated on the northern part of the island of Sylt, North Sea. The bounded area corresponds to that shown in the aerial photographs of Figure $9 a, b$

Aerial photography can'thus be viewed as a relatively cheap and effective compromise between satellite imagery and high resolution spectrometers for remotely sensing the Wadden Sea.

The present aerial survey was undertaken to assess the value of true-colour aerial photography for deriving estimates of distributional differences and changes in surface characteristics over time.

For this probationary phase we are focussing on the dominant macrophyte species, which include the sea grass Zostera marina/Z. noltii, and the macroalgae Enteromorpha spp. and Ectocarpus spp. These species are known to be of great ecological importance in the area chosen for this study. This is the Königshafen area which lies on the northern tip of the island of Sylt, North Sea (Fig. 8).

Surveys were carried out on 16 June 1988 (summer sample) and 18 September 1988 (autumn sample), at altitudes of $2500 \mathrm{ft}$, and $2500 \mathrm{ft}$ and $5000 \mathrm{ft}$, respectively.

In conjunction with the aerial surveys, quantitative ground surveys were undertaken. These were carried out monthly between June and December $1^{\text {noo }}$ n...nutitnti... mam 


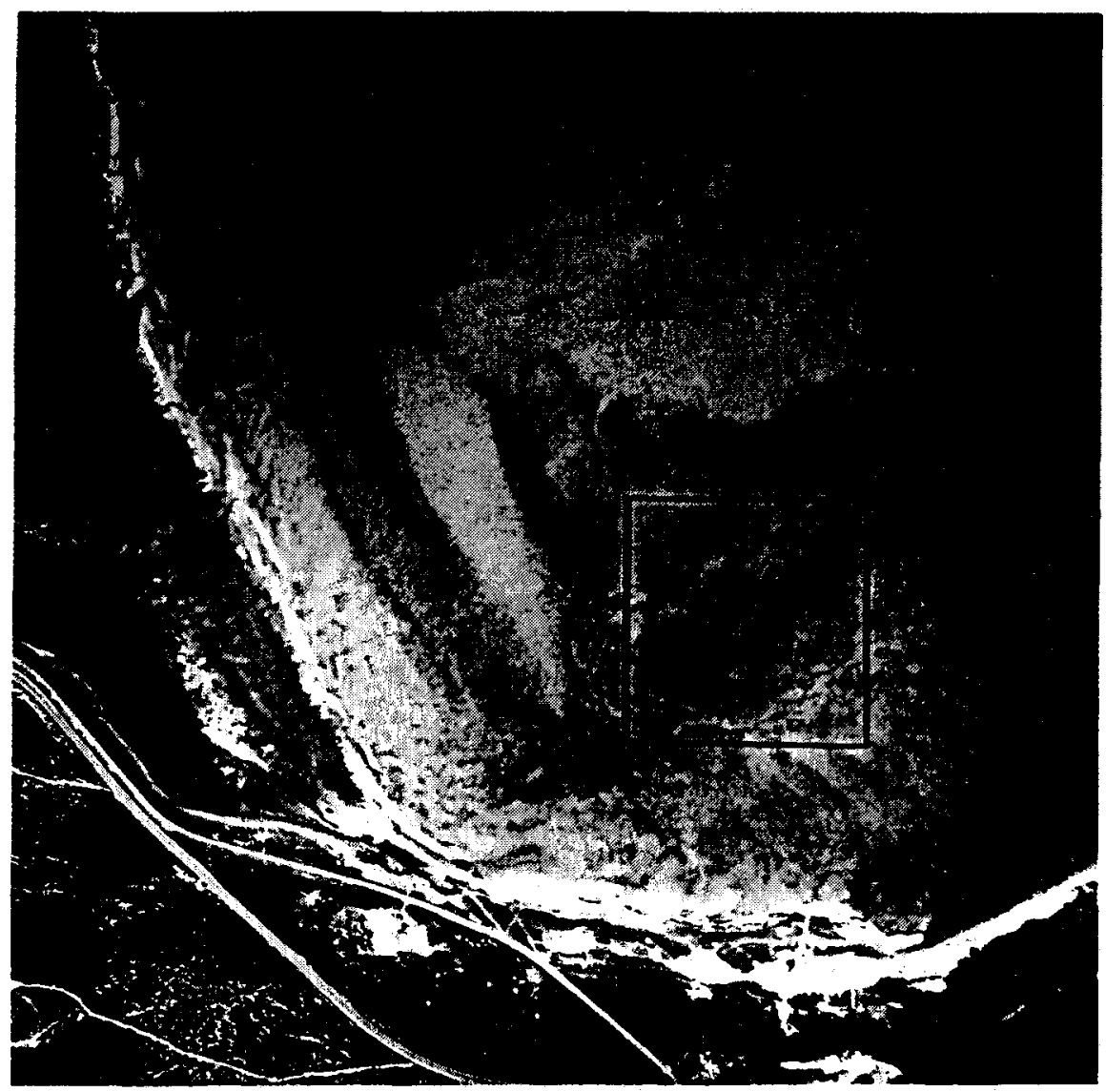

Fig. 9a. Summer aerial photograph of an area in Königshafen. The bordered area $\left(200 \mathrm{~m}^{2}\right)$ was digitised for classification purposes (Permission given by Luftamt Hamburg, Nr. 818/89)

ples of percentage cover were obtained from an area $30 \mathrm{~m} \times 30 \mathrm{~m}$ within the bounded area shown in Figures 9a, 9b. A grid system was set up to include 49 sampling points, corresponding to a between-sample distance of $5 \mathrm{~m}$. At each sampling point a $0.25 \mathrm{~m}^{2}$ grid (further divided into $0.01 \mathrm{~m}^{2}$ units) was photographed and used for estimating percentage cover.

By comparing summer and autumn images (Fig. 9a, b), it is clear that a considerable change has occurred in the distribution pattern of the species named above. Translating this change into what was found in the $30 \mathrm{~m} \times 30 \mathrm{~m}$ grid shows there was a decrease in the overall percentage cover in this area, from $49.99 \%$ in summer to $24.69 \%$ in autumn. This change can be further divided in terms of the proportions of the two dominating genera. Enteromorpha spp. dominated (45.24\% of total cover) during the summer period (Fig. 10a), while Zostera spp. contributed very little to the overall cover with $4.75 \%$ for the same period (Fig. 10b). In autumn, however, the pattern is reversed and Zostera spp. become the dominant cover $(23.04 \%$; Fig. 11b) with Enteromorpha spp. being almost absent (1.65\%; Fig. 11a). 


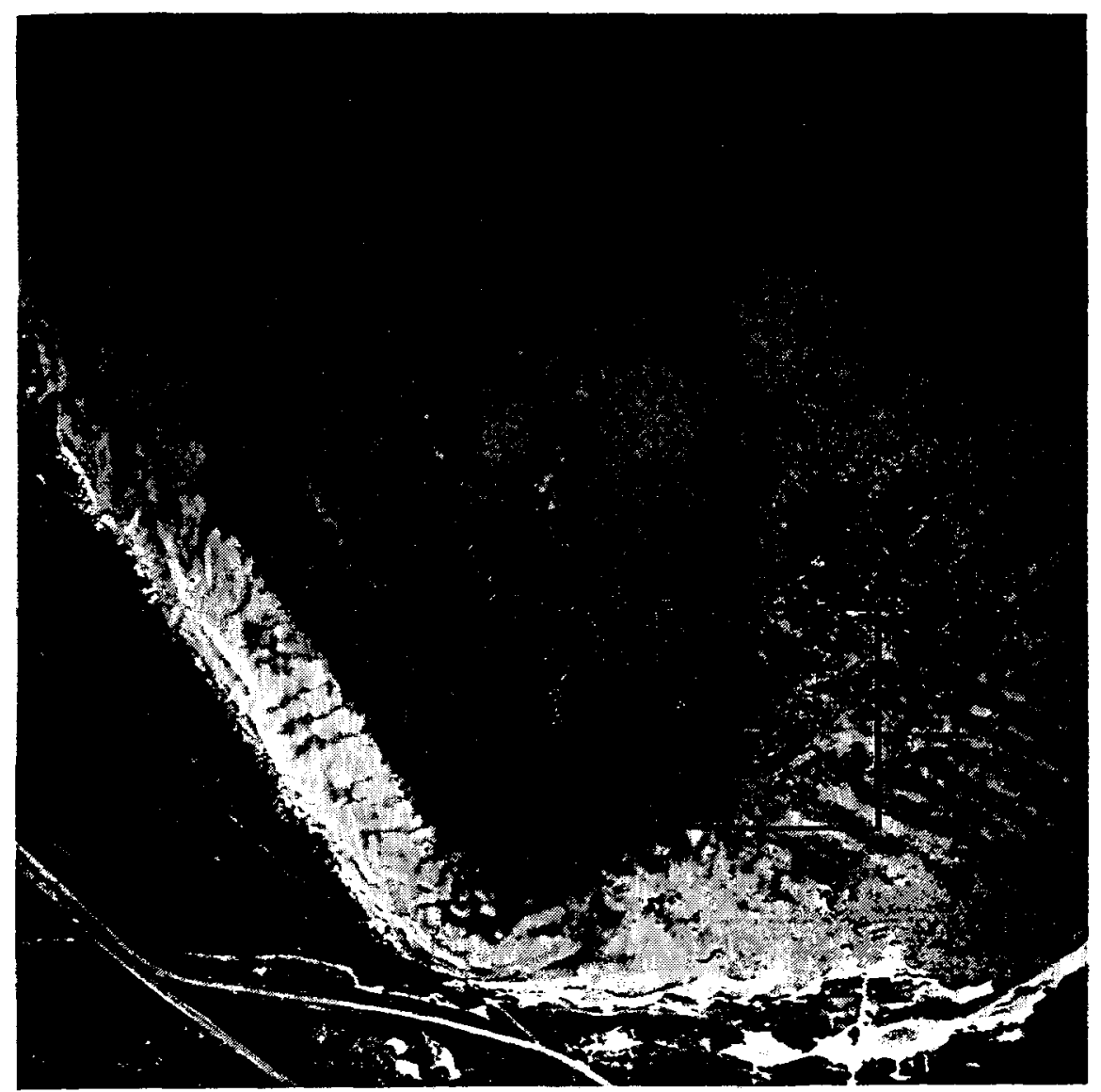

Fig. 9b. Autumn aerial photograph of an area in Königshafen. The bordered area $\left(200 \mathrm{~m}^{2}\right)$ was digitised for classification purposes (Permission given by Luftamt Hamburg, Nr. 818/89)

These more subtle changes are presently being assessed using the aerial photographs which when digitised have a ground resolution of approximately $40 \mathrm{~cm}$. It is clear from these photographs that a difference in the horizontal distribution of classes exists; however, further work is required before we can definitely say what each class represents. We can, however, tentatively say that out of five statistically different classes present during both summer and autumn periods, we have recognised at present three macrophyte "types" during the summer period and two macrophyte "types" during the autumn period. From our knowledge of the area we can also say that the differences in class distinction over all five classes is due either to differences in percentage cover per unit area, differences caused by a combination of macrophyte cover with variable water cover, or due to differences in the relative percentage overlap of the different plant species present. As they stand, the percentage cover of each of the class "types" can be easily obtained using existing methodology. 

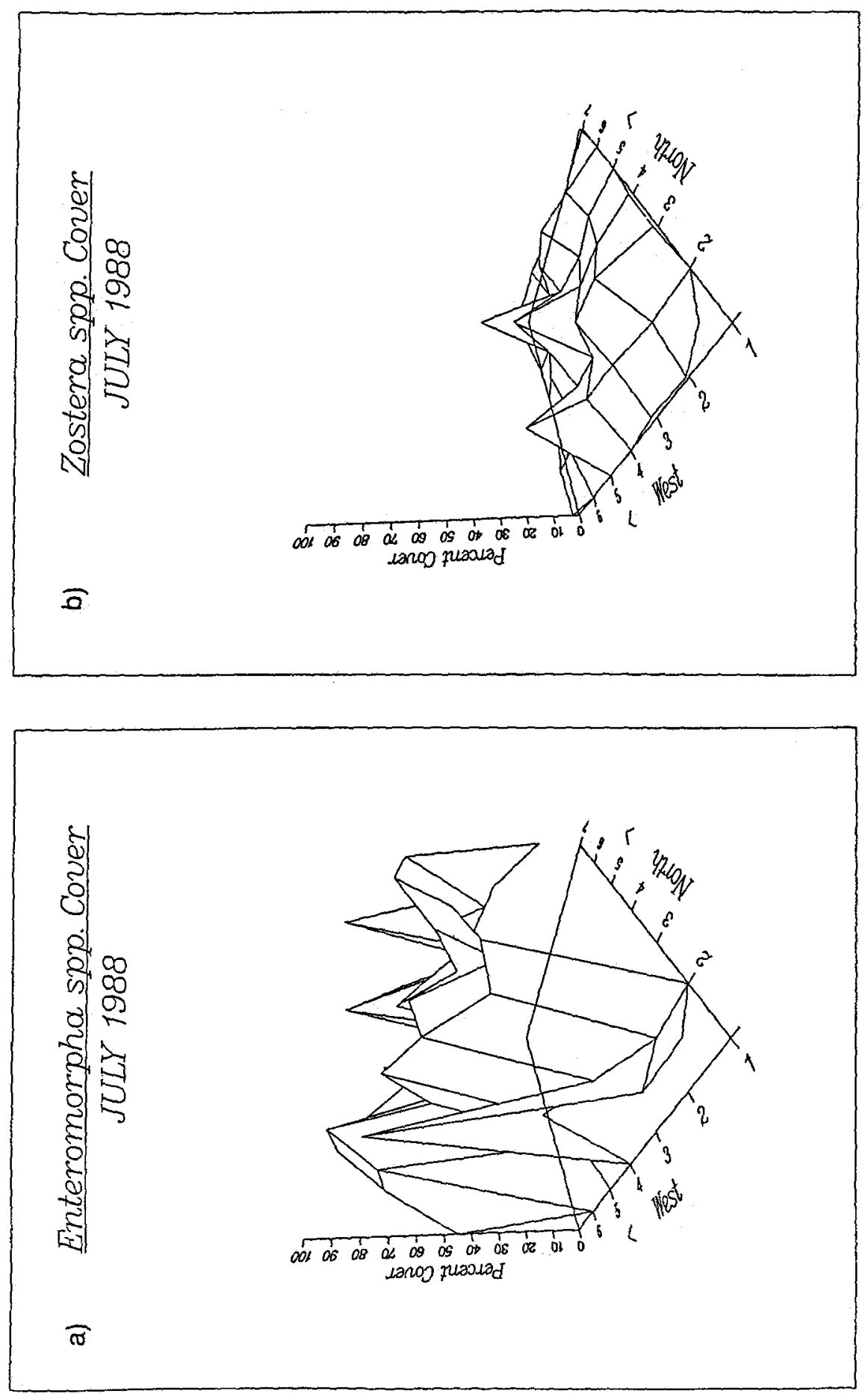

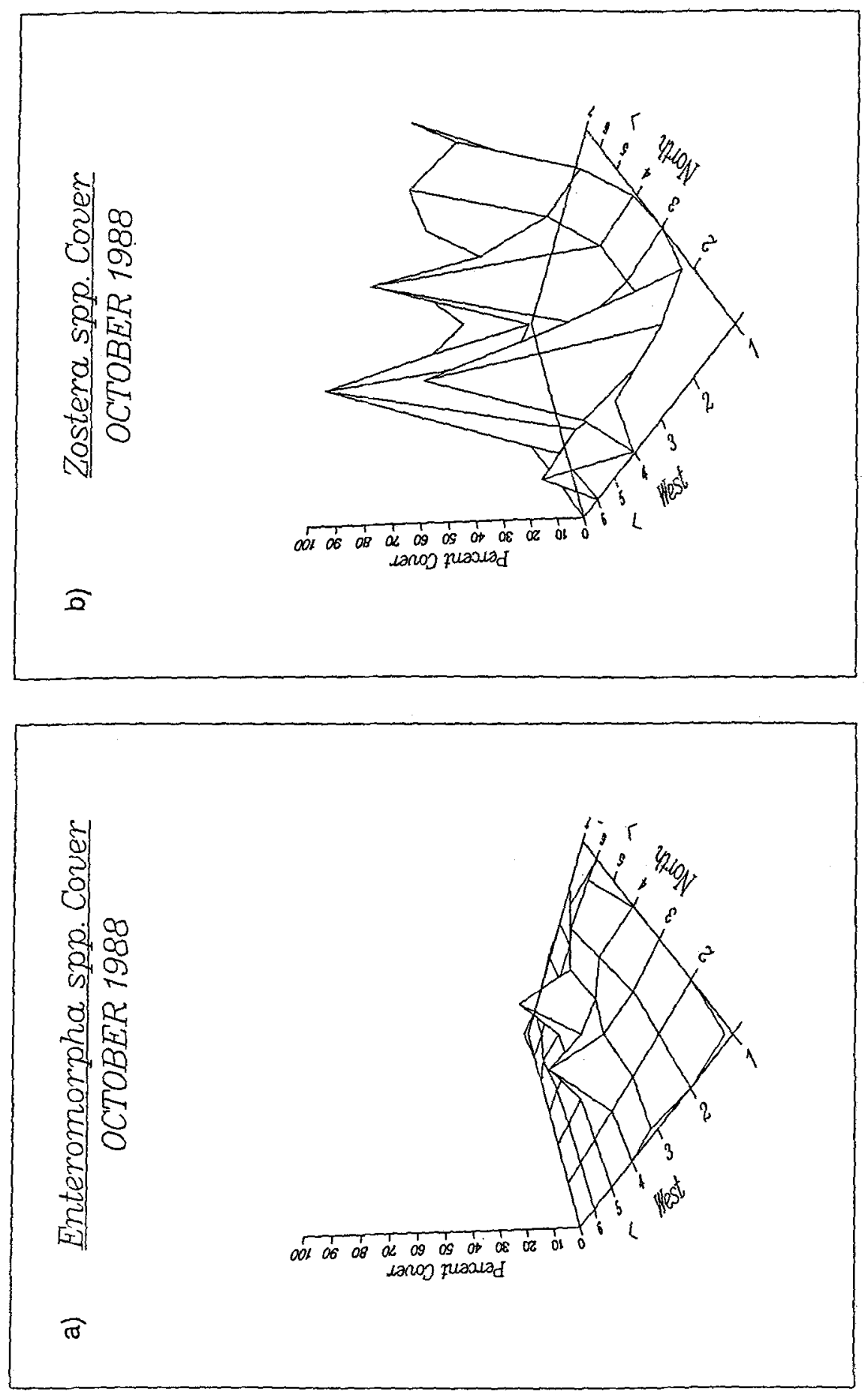

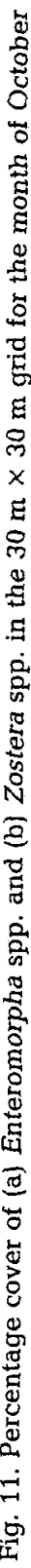




\section{CONCLUSIONS AND SUMMARY}

Whereas other studies, with a similar emphasis on using multispectral satellite data have focussed mainly on resolving differences in the type of sediment present, we have tried to focus on the main factors or sources underlying the combined spectral variation in the seven TM channels.

We have been able to make a clear separation of the tidal flat using a combination of TM channels 4, 5 and 6 . Since no direct derivation of surface types is possible from pixels which have a mixed substructure, the tidal flat class only was used in a factor analysis (i.e. water, land, foreland and cloud classes were masked-out). Three factors were obtained which together accounted for $82 \%$ of the total variation in all seven TM channels. The results strongly suggest that topography (i.e. by the combination of covarying variable influences) is the most important factor to be retrieved. The second most important factor is that of the water content of the sediment, followed by the surface temperature of the sediment.

Following these results it can thus be argued that apart from mapping proximate factors underlying the distribution of surface types, factor analysis can be used to detect temporal changes and assist in the problem of obtaining samples which are representative for a given area. To do this, however, ground verification is necessary. The importance of long-term temporal changes in sediment morphology in terms of the presence and distribution of organisms is highlighted by Reise et al. (1989). Remotely mapping tidal flat sediment type and structure is best done during the winter months when macrophyte cover is at a minimum.

Aerial photography, with its high spatial resolution, has been used for mapping the distribution of sea grass and macroalgae on the tidal flat. Changes in the large-scale (i.e. between-pixel) distribution of these macrophytes over time is clear from a visual interpretation of the aerial photographs. These distributional changes can be translated into changes in the overall percentage cover of all dominant species present. A simultaneous change in species dominancy also occurred during this period. In the context of an ecological research programme which includes remote sensing, the need for a parameterisation of these changes for understanding the underlying processes causing these changes, highlights the need for time series analysis.

Subsequent to digitising the aerial photographs, the determination of different macrophyte types has, to date, been inconclusive, however, it is possible with existing methods to obtain quantitative estimates of the percentage cover of each class and for the purposes of estimating spatio-temporal scales of patchy distributions, to alter the spatial scale of analysis. Before this can be undertaken, however, class types must be verified. The resolution of variable water coverage, or even the presence or absence of water cover, is one problem which must be overcome before a definitive classification of important classes is possible.

Acknowledgements. We would like to thank H. Bianchi of the International Bureau, GKSS, for the financial support given to D. Murphy during the initial stages of this research. Thanks are due to K. Heymann for her expert work in digitising and processing the plates, and to Professor H. Graßl for his initial stimulus and subsequent interest in this research. 


\section{LITERATURE CITED}

Anderson, R. J. \& Wobber, F. J., 1973. Wet land mapping in New Jersey. - Photogramm. Engng Remote Sens, 34, 353-358.

Bartholdy, J. \& Folving, S., 1986. Sediment classification and surface type mapping in the Danish Wadden Sea by remote sensing. - Neth. J. Sea Res. 20, 337-345.

Cameron, H. L., 1950. The use of aerial photography in seaweed studies. - Photogramm. Engng 16, 493-501.

Cattell, R. B., 1977. Factor analysis: an introduction and manual for the psychologist and social scientist. Greenwool Press, Connecticut, $462 \mathrm{pp}$.

Dennert-Möller, E., 1983. Untersuchungen zur digitalen multispektralen Klassifizierung von Fernerkundungsaufnahmen mit Beispielen aus den Wattgebieten der deutschen Nordseeküste. Diss. Univ. Hannover, $96 \mathrm{pp}$.

Doerffer, R., Fischer, J., Stössel, M., Brockmann, C. \& Grassl, H., 1989. Small scale patches of suspended matter and phytoplankton in the Elbe river estuary, German Bight and tidal flats. Adv. Space Res. 9 (1), 191-200.

Folving, S., 1984. The Danish Wadden Sea. - Folia geogr. dan. 15 (2), 1-56.

Grimes, B. H., 1971. A comparison of film type and the importance of season for interpretation of coastal marshland. - Photogramm. Rec. 7, 213-222.

Gross, M. F., Klemas, V. \& Levasseur, J. E., 1988. Remote sensing of biomass of salt marsh vegetation in France. - Int. J. Remote Sens. 9, 397-408.

Harman, H. H., 1976. Modern factor analysis. Univ. of Chicago Press, Chicago, $487 \mathrm{pp}$.

Hubbard, J. C. E. \& Grimes, B. H., 1972. The analysis of coastal vegetation through the medium of aerial photography, - Med. biol. Illust. 22, 182-190.

Maxwell, A. E., 1977. Multivariate analysis in behavioural research. Monograph in Applied Probability and Statistics. Chapman \& Hall, London, $164 \mathrm{pp}$.

Meulstee, C., Nienhuis, P. H. \& Stokkom, H. T. C. van, 1986. Biomass assessment of estuarine macrophytobenthos using aerial photography. - Mar. Biol. 91, 331-335.

Meulstee, C., Nienhuis, P. H. \& Stokkom, H. T. C. van, 1988. Aerial photography for biomass assessment in the intertidal zone. - Int. J. Remote Sens. 9, 1859-1867.

Michaelis, H., Ragutzki, G. \& Ramm, G., 1982. Sedimentologische und biologische Untersuchung der Watten des Jadebusens. - Intermaritec 82, 738-748.

Pestrong, R., 1969. Multiband photos for a tidal marsh. - Photogramm. Engng 35 (5), 453-470.

Reimold, R. J., Gallaher, J. L. \& Thompson, D. E., 1973. Remote sensing of tidal marsh. - Photogramm. Engng 34, 477-488.

Reise, K., Herre, E. \& Sturm, M., 1989. Historical changes in the benthos of the Wadden Sea around the island of Sylt in the North Sea. - Helgoländer Meeresunters. 43, 275-293.

Rose, P. \& Schulz, R., 1978. Klassifizierung von Objekten multispektraler Bilder mit unsupervised Methoden unter besonderer Berücksichtigung der natürlichen Texturen. - Tech. Rep. Tech. Univ. Berlin, Forschungsvorhaben 01 QS 496-ZA/SNA-WE 02 75-4.2.

Rummel, R. J., 1970. Applied factor analysis. Northwestern Univ. Press, Evanston, 617 pp.

Sehers, J. S. \& Tueller, P. T., 1973. Color aerial photos for marshland. - Photogramm. Engng 34, $489-499$.

Späth, H., 1975. Cluster-Analyse-Algorithmen. Oldenbourg, München, $217 \mathrm{pp}$.

Steffensen, D. A. \& McGregor, F. E., 1976. The application of aerial photography to estuarine ecology. - Aquat. Bot. 2, 3-11.

Überla, K., 1971. Faktorenanalyse. Springer, Berlin, 399 pp.

Wallentinus, H. \& Jonson, L., 1972. Mapping vegetation of a Baltic sea-shore meadow by colour infrared photography. - Svensk bot. Tidskr. 66, 314-325.

Wegener, B., 1979. Rechnergestützte Erfassung und Beschickung von Wasserlinien im Verfahren der Wattvermessung. Diss. Univ. Hannover.

Wieland, P., 1984. Fernerkundung als Hilfsmittel in der Wattenforschung. - Küste 40, 91-106. 